\title{
THE EFFECT OF ESTROGENS UPON THE PERIPHERAL METABOLISM OF THYROXINE * $\dagger$
}

\author{
By J. THOMAS DOWLING, $\ddagger$ NORBERT FREINKEL AND SIDNEY H. INGBAR
}

\author{
(From the Thorndike Memorial Laboratory, Second and Fourth (Harvard) Medical Services, \\ Boston City Hospital; the Department of Medicine, Harvard Medical School, Boston, \\ Mass.; the Howard Hughes Medical Institute, the Department of Medicine, \\ Veterans Administration Center, Los Angeles; and the Department of \\ Medicine, University of California Medical Center, \\ Los Angeles, Calif.)
}

(Submitted for publication August 13, 1959; accepted March 25, 1960)

In plasma, thyroxine is avidly bound to specific proteins present in low concentration, particularly the so-called thyroxine-binding globulin (TBG) and thyroxine-binding pre-albumin (TBPA) (1-4). Several observations indicate that such protein-hormone interactions are of physiological importance. In vitro, the ability of cellular systems to accumulate thyroxine from suspending media is conditioned by the thyroxine-binding potency of the proteins within the media $(5,6)$. In addition, the volume of distribution and rate of turnover of thyroxine in vivo resemble those of certain plasma proteins $(7,8)$. Finally, abnormal thyroxine-binding by TBG and TBPA has been observed in a variety of states in which the peripheral metabolism of thyroid hormone is disturbed (9-12). It therefore seemed possible that interactions with plasma proteins might in part regulate the peripheral utilization and degradation of thyroxine.

An ideal test of this hypothesis would be provided by studies of hormonal metabolism performed before and during the administration of large quantities of purified binding protein. However, adequate quantities of these materials are not yet available. Therefore, it. has been necessary to assess the effects of alterations in thyroxinebinding induced by pharmacological means. Large

\footnotetext{
* Presented in part at the Annual Meeting of the American Goiter Association, San Francisco, Calif., June 16, 1958.

$\dagger$ This investigation was supported in part by Research Grant no. A-267 from the National Institute of Arthritis and Metabolic Diseases, Bethesda, Md., and in part by the Medical Research and Development Board, Office of the Surgeon General, Department of the Army, under Contract no. DA-49-007-MD-412.

$\ddagger$ Work performed in part during tenure as a Fellow in Cancer Research of the American Cancer Society.
}

doses of estrogen have been shown to induce pronounced increases in the thyroxine-binding activity of TBG (13), with little or no change in the binding activity of TBPA (14). The present studies concern the effects of estrogens and of the increase in thyroxine-binding by TBG which they induce on the peripheral metabolism of thyroxine in patients with diverse states of thyroidal function.

\section{MATERIAL AND METHODS}

By means of techniques described in detail elsewhere (7), the distribution and peripheral turnover of $\mathrm{I}^{131}$-labeled thyroxine ${ }^{1}$ have been assessed before and during maximum estrogen-induced increase in circulating TBG. Definitions of terms employed and their mode of calculation are noted in the appendix. Patients studied included 8 women with treated myxedema, 3 with intact thyroidal function, and 4 with thyrotoxic Graves' disease. In 10 of the eumetabolic patients, paired studies were performed before and during the administration of diethylstilbestrol. Comparison of the effects of diethylstilbestrol and estradiol benzoate were made in 5 of these patients.

The sequence of the study periods, details of thyroidal replacement therapy, and dosage and duration of estrogenic therapy in each subject are presented in Table I. Duration of estrogenic therapy ranged between 19 and 54 days, and measurements of thyroxine turnover during periods of estrogenic therapy were performed during the last 8 to 10 days of the treatment period. Subjects with intact thyroidal function, excepting V.D., were given 30 $\mathrm{mg}$ of methimazole by mouth every 6 hours during each study period in order to prevent thyroidal recycling of $I^{131}$ liberated by peripheral deiodination of radioactive thyroxine. The serum protein-bound iodine $(\mathrm{PBI})^{2}$ and thyroxine-binding activity of TBG were assessed at 3 day intervals throughout control and treatment periods.

\footnotetext{
1 Obtained from Abbott Laboratories, Oak Ridge, Tenn.

2 Determined by Bio-Science Laboratories, Beverly Hills, Calif.
} 


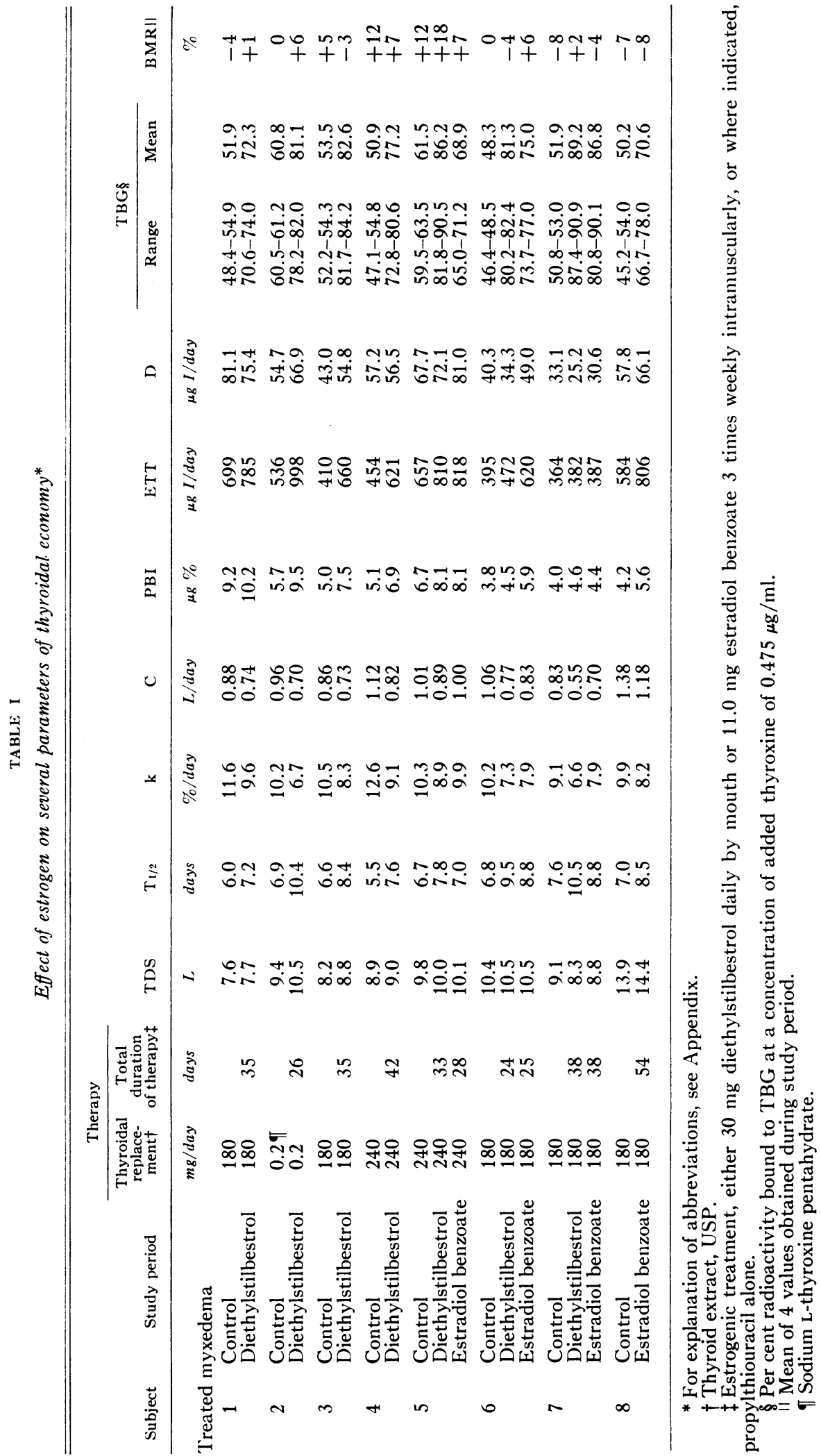




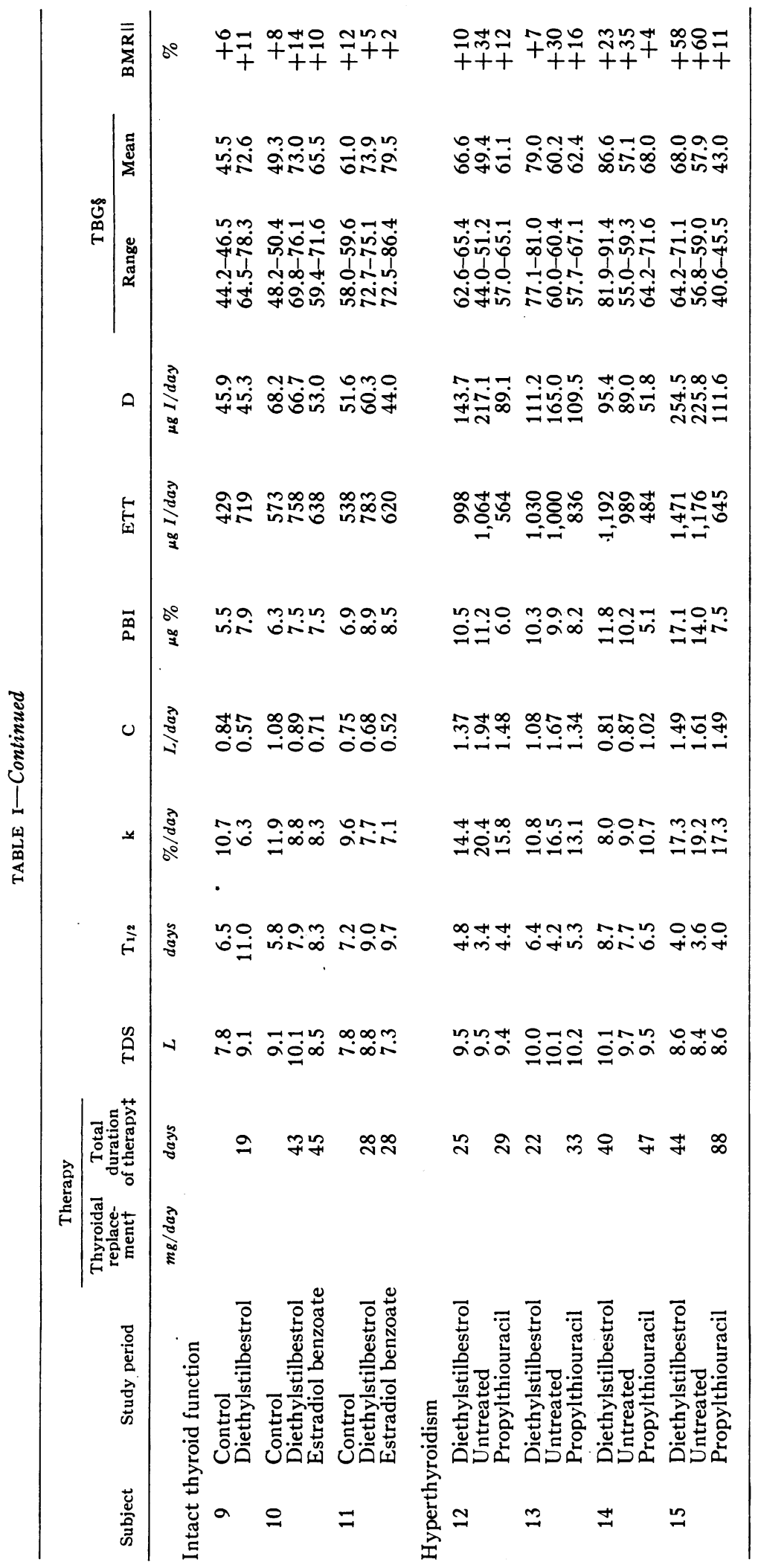


TABLE II

Effect of estrogens on the fecal excretion and degradation of thyroxine*

\begin{tabular}{|c|c|c|c|c|c|c|c|c|c|c|}
\hline \multirow[b]{2}{*}{ Patient } & \multicolumn{2}{|c|}{$F_{\max }$} & \multicolumn{2}{|c|}{ Fecal clearance } & \multicolumn{2}{|c|}{ Degradative clearance } & \multicolumn{2}{|c|}{ Fecal excretion } & \multicolumn{2}{|c|}{ Degradative rate } \\
\hline & Control & Estrogen & Control & Estrogen & Control & Estrogen & Control & Estrogen & Control & Estrogen \\
\hline & \multicolumn{2}{|c|}{$\%$ dose } & \multicolumn{2}{|c|}{$L /$ day } & \multicolumn{2}{|c|}{$I . / d a y$} & \multicolumn{2}{|c|}{$\mu g I /$ day } & \multicolumn{2}{|c|}{$\mu g I /$ day } \\
\hline 1 & 27.5 & 38.9 & 0.24 & 0.29 & 0.64 & 0.45 & 22.4 & 29.3 & 58.7 & 46.1 \\
\hline 2 & 37.4 & 40.6 & 0.36 & 0.29 & 0.60 & 0.42 & 20.5 & 27.2 & 34.2 & 39.7 \\
\hline 3 & 29.8 & 28.7 & 0.26 & 0.21 & 0.60 & 0.52 & 12.8 & 15.8 & 39.7 & 30.2 \\
\hline 4 & 42.0 & 29.5 & 0.47 & 0.24 & 0.65 & 0.58 & 24.0 & 16.6 & 33.1 & 39.9 \\
\hline 5 & 23.2 & 16.2 & 0.23 & 0.14 & 0.78 & 0.75 & 15.7 & 11.7 & 51.9 & 60.4 \\
\hline 8 & 21.6 & 9.6 & 0.30 & 0.11 & 1.08 & 1.07 & 12.5 & 6.3 & 45.3 & 59.8 \\
\hline 10 & 26.7 & 26.2 & 0.29 & 0.23 & 0.79 & 0.66 & 18.2 & 17.5 & 50.0 & 49.2 \\
\hline Mean & 29.7 & 27.1 & 0.31 & 0.22 & 0.74 & 0.63 & 18.0 & 18.1 & 43.3 & 47.7 \\
\hline Mean diff. & \multicolumn{2}{|c|}{-2.6} & \multicolumn{2}{|c|}{-0.09} & \multicolumn{2}{|c|}{-0.10} & \multicolumn{2}{|c|}{+0.1} & \multicolumn{2}{|c|}{+4.4} \\
\hline SEMD $\dagger$ & \multicolumn{2}{|c|}{3.3} & \multicolumn{2}{|c|}{-0.035} & \multicolumn{2}{|c|}{-0.027} & \multicolumn{2}{|c|}{2.2} & \multicolumn{2}{|c|}{3.3} \\
\hline $\mathrm{p}$ & \multicolumn{2}{|c|}{$>0.4$} & \multicolumn{2}{|c|}{$<0.05$} & \multicolumn{2}{|c|}{$<0.01$} & \multicolumn{2}{|c|}{$>0.5$} & \multicolumn{2}{|c|}{$>0.2$} \\
\hline
\end{tabular}

* For definition of terms, see Appendix.

$\dagger$ Standard error of the mean difference.

Studies of thyroxine turnover during the treatment period were begun when a new steady state had been achieved, as indicated by constancy of values for TBG and PBI. Values for TBG presented in Table I represent the range and mean of 4 to 5 measurements made during control or steady state treatment periods.

Additional studies were performed during periods in which the PBI and the binding activity of TBG were changing after the initiation or withdrawal of estrogenic hormone. In Patient 6, the fractional rate of peripheral turnover of thyroxine was observed during a 24 day period beginning immediately after institution of treatment with diethylstilbestrol. Patient 9 was studied from the fifth through the eighteenth day following cessation of therapy with diethylstilbestrol.

The 4 women with thyrotoxicosis were studied while hospitalized on a metabolic ward. Diethylstilbestrol was administered only after constancy of basal oxygen consumption had been achieved. After attainment of maximal augmentation in TBG during the administration of estrogen, studies were again performed. Thereafter, all therapy was discontinued until TBG levels, concentrations of PBI and TBG, and basal oxygen consumption stabilized at values comparable to those found prior to estrogenic treatment. Thyroxine turnover studies were then repeated. At the termination of these tests, the patients were given propylthiouracil in dosage and duration sufficient to induce clinical and laboratory evidences of eumetabolism. Studies of peripheral turnover of thyroxine were then repeated.

Estimates of the thyroxine-binding activity of TBG were obtained by means of a technique, described in detail elsewhere (15), which has since been superseded in the authors' laboratories (4). In brief, the method employed consisted of conventional paper electrophoresis in veronal buffer, $\mathrm{pH} 8.6$, of serum labeled with $\mathrm{I}^{231}$-thyroxine and enriched to several standard concentrations with stable thyroxine. At each concentration, the percentage distribution of added hormone between TBG and albu- min was assessed in both experimental sera and concomitantly electrophoresed control sera. As indicated in an earlier communication (15) alterations in the binding activity of TBG are associated with qualitatively similar changes in the distribution of thyroxine between TBG and albumin at each of the concentrations of hormone employed. Therefore, only values obtained at a single concentration, $47.5 \mu \mathrm{g}$ thyroxine per $100 \mathrm{ml}$, are presented. This technique does not afford an estimate of the absolute thyroxine-binding capacity of TBG. Nevertheless, comparison of changes in TBG which occur during pregnancy, assessed by this method (15) and by methods which permit estimation of binding maxima (16), indicate that the two techniques provide qualitatively similar information. ${ }^{3}$

Statistical analyses were performed by the "paired $t$ " test, as described by Snedecor (17). An earlier study suggested that the presence of a functioning thyroid gland does not alter the kinetics of thyroxine turnover peripherally, since values for normal subjects and patients with treated myxedema were similar (7). Therefore, in the present studies, results related to the effects of estrogen on the peripheral turnover of thyroxine in all eumetabolic normal and athyrotic subjects were pooled.

\section{RESULTS}

Data obtained in individual patients are presented in Tables I and II. Mean values and statistical intercomparisons are summarized in Tables II and III.

3 Neither estimates of the thyroxine-binding activity of TBG, as herein obtained, nor of its absolute binding capacity afford information concerning the absolute quantity of protein present. Presumably, alterations in binding activity may reflect changes in either the concentration of TBG or its binding stoichiometry. 


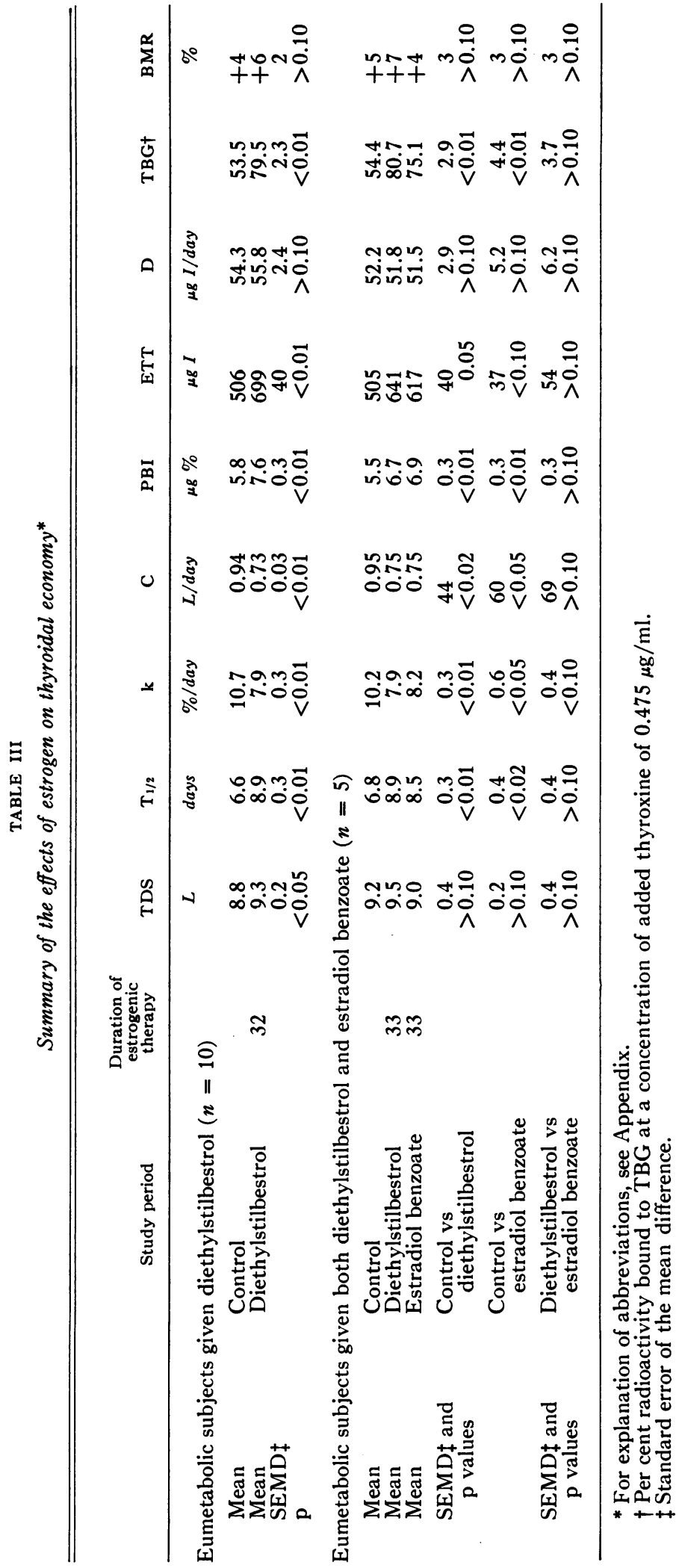


Eumetabolic subjects. Previously described effects of large doses of estrogen on PBI $(13,18)$ and on the binding activity of TBG (13) were confirmed in the present study. Increases in PBI during estrogenic therapy occurred not only in patients with intact thyroidal function, but also in patients with treated myxedema. For the entire group, mean values of the PBI increased from 5.8 to $7.6 \mu \mathrm{g}$ per $100 \mathrm{ml}$. For the patients with treated myxedema alone, PBI increased significantly $(\mathrm{p}<0.001)$ from a mean of 5.5 to $7.1 \mu \mathrm{g}$ per $100 \mathrm{ml}$. Concomitantly, in sera enriched with stable thyroxine at a concentration of $47.5 \mu \mathrm{g}$ per $100 \mathrm{ml}$, the proportion of radioactive thyroxine bound to TBG increased from a mean of 54.4 to 79.5 per cent.

In ten paired observations, diethylstilbestrol increased the mean thyroxine distribution space (TDS) from 8.8 to $9.3 \mathrm{~L}$, a change of borderline statistical significance. Mean thyroxine half-time $\left(\mathrm{T}_{\frac{1}{2}}\right)$ also increased from 6.6 to 8.9 days, while the fractional rate of turnover of hormone $(\mathrm{k})$ correspondingly decreased from 10.7 to 7.9 per cent per day. Despite the increase in TDS, mean daily thyroxine clearance (C) decreased from
0.94 to $0.73 \mathrm{~L}$ per day. The product of daily hormonal clearance rate (C) and hormonal concentration (PBI) represents the quantity of hormonal iodine removed from the peripheral thyroxine space daily (D). As a result of reciprocal changes in its constituent functions, D remained unchanged during estrogenic therapy in the group as a whole. Small, random differences between control and treatment values of $\mathrm{D}$, noted in individual patients, were probably the result of errors intrinsic to the technique of measurement. Following equilibration of PBI and TBG, basal oxygen consumption during estrogenic treatment did not differ from control values.

As a result of increases in both TDS and PBI, the mean quantity of exchangeable (extrathyroidal) hormonal iodine (ETT) increased significantly from 506 to $699 \mu \mathrm{g}$ during administration of estrogen. Derived values for the fraction of total hormonal disposal accounted for by fecal excretion $\left(\mathrm{F}_{\max }\right)$ did not change significantly for the group as a whole.

In the five patients who received both types of estrogen, significant differences in the effects of

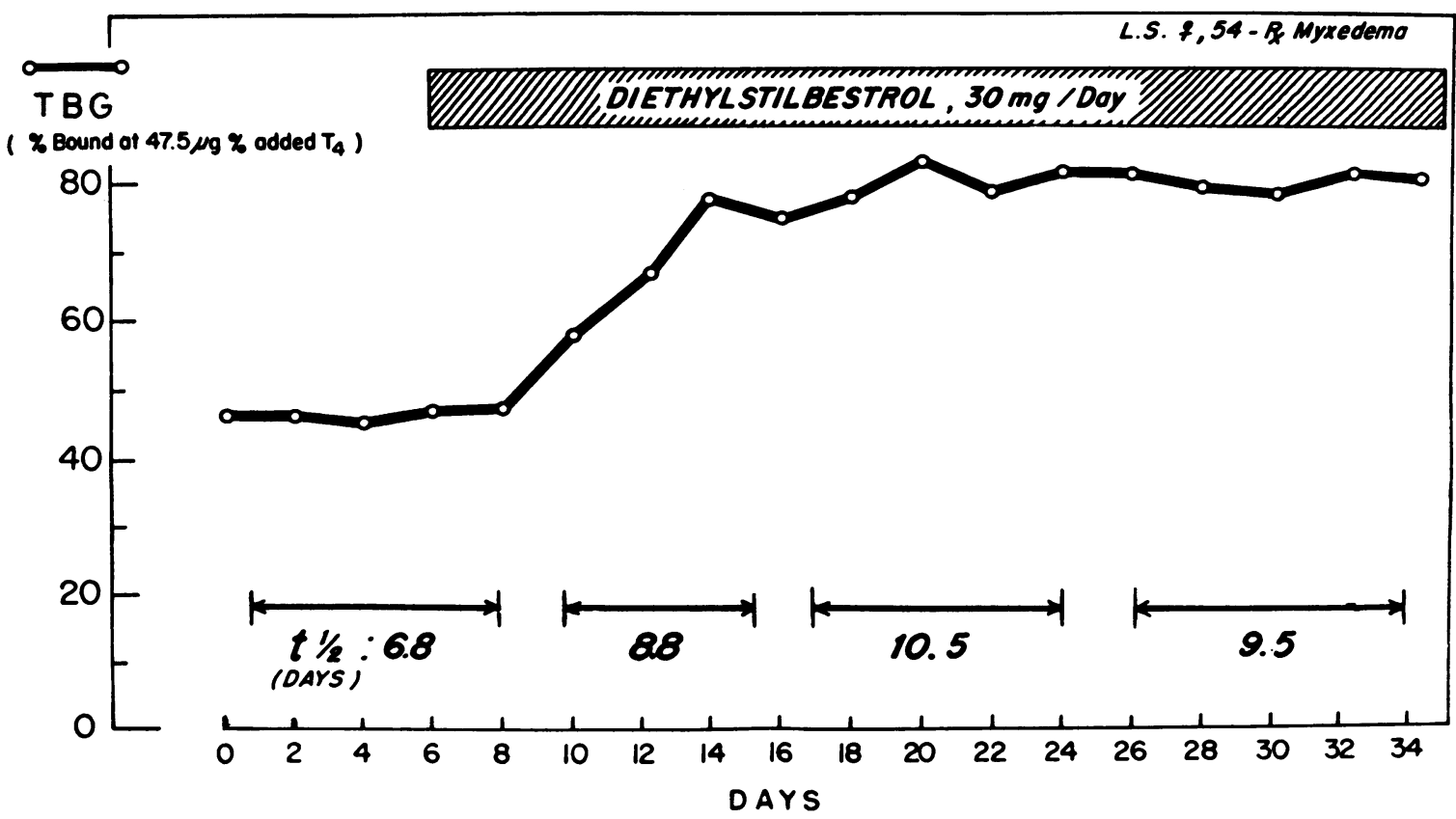

Fig. 1. The relationship of estrogen-induced increases in the binding avidity of TBG to Changes in

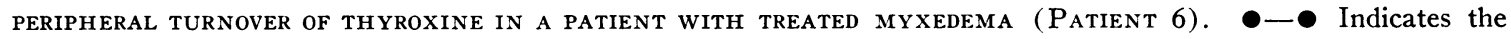
percentage of added $\mathrm{I}^{131}$-labeled thyroxine migrating with TBG during paper electrophoresis of serum enriched with stable thyroxine at a concentartion of $47.5 \mu \mathrm{g}$ per $100 \mathrm{ml}$. 


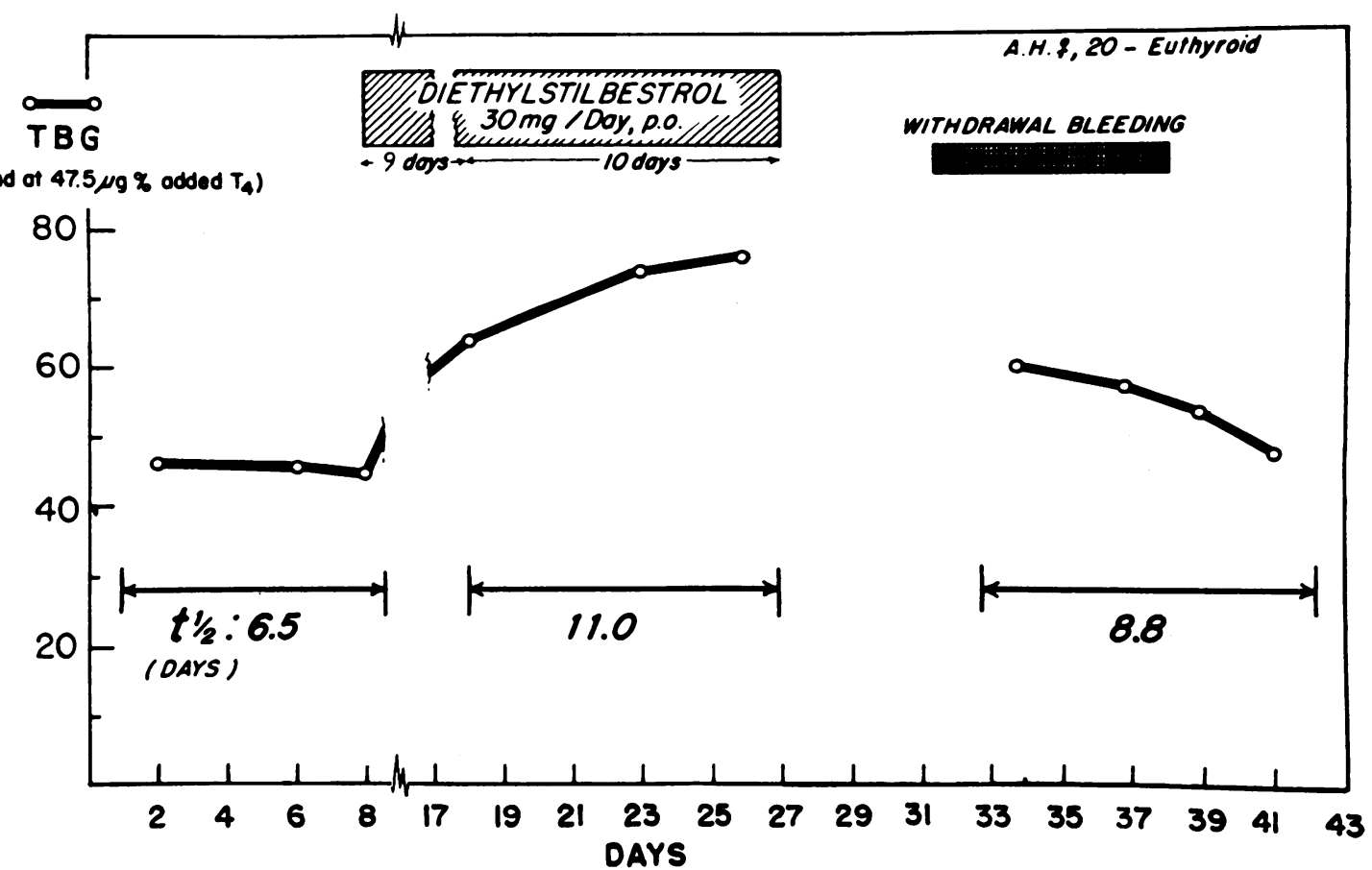

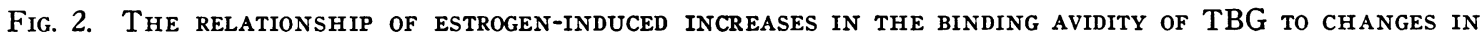
PERIPHERAL TURNOVER OF THYROXINE IN A EUTHYROID PATIENT (PATIENT 9).

diethylstilbestrol and estradiol benzoate could not be discerned.

Studies performed in Patient 6 throughout the 24 day period following initiation of estrogenic therapy, and in Patient 9 following cessation of treatment, are depicted in Figures 1 and 2 . In Patient 6 the control rate of peripheral turnover of thyroxine was 10.2 per cent per day and was followed in successive weeks by rates estimated to be $7.9,6.6$, and 7.3 per cent per day. Increases in thyroxine-binding by TBG were detected on the fourth day of administration of diethylstilbestrol, and reached a maximum after 14 days. In Patient 9, following a pretreatment rate of 10.7 per cent per day, the fractional rate of turnover of thyroxine decreased to 6.6 per cent per day during continued estrogenic therapy. After cessation of treatment, increased thyroxine-binding by TBG persisted for a time and turnover rate remained retarded at 7.3 per cent per day, although withdrawal vaginal bleeding had occurred.

Administration of diethylstilbestrol to the women with Graves' disease was also accompanied by slowing of the fractional rate of peripheral turnover of thyroxine (Table I). In all four pa- tients, this rate was as slow or slower than that subsequently observed after antithyroid treatment. In Patients 12 and 13, estrogenic therapy was accompanied by amelioration of symptoms of thyrotoxicosis and by reduction of basal metabolic rates to normal. In these patients, in contradistinction to the two patients who experienced no symptomatic benefit, PBI was unchanged or decreased during estrogenic therapy as compared to control periods. Correspondingly, calculated values for daily hormonal disposal (D) in these two women were markedly reduced, approaching values obtained after treatment with antithyroid drugs.

\section{DISCUSSION}

In agreement with the recently published findings of Engbring and Engstrom (19), the present studies seem clearly to indicate that the prolonged administration of either natural or synthetic estrogenic hormones is associated with pronounced changes in the peripheral metabolism of thyroxine. These include a decrease in the fractional rate of turnover of thyroxine and hence in the rate of clearance of the hormone from its peripheral dis- 
tribution space. Concomitantly, both the concentration and total quantity of hormone within the space increase, so that the absolute rate of hormonal disposal remains unchanged. These studies, however, were undertaken to assess the kinetic effects of an increase in the thyroxine-binding activity of TBG. Estrogens were merely employed as a means of altering TBG. Thus, it is critical to distinguish between changes in the kinetics of thyroxine metabolism which resulted from alterations in TBG and those which might have arisen from a direct effect of estrogens on the cellular degradation or disposal of the hormone.

Certain data suggest that estrogens may directly influence cellular oxidative metabolism and its response to thyroid hormone. While estrogens generally stimulate genital structures, several estrogens have been found to depress oxygen consumption of homogenates of rat brain (20) and liver (21), and of fresh rat liver mitochondria incubated with Krebs' cycle intermediates and diphosphopyridine nucleotide (22). Animals treated with estrogen have been reported to be unusually resistant to large doses of thyroid hormone (2326), and diethylstilbestrol has been shown to hasten the return of oxygen consumption to normal following cessation of thyroid feeding in rats (27). However, it is not known whether such effects on oxidative metabolism might result from or lead to changes in the intracellular metabolism of thyroxine. More direct efforts to evaluate this question have led to contradictory conclusions, since estrogens have had variable effects on the degradation of thyroxine by cellular preparations, in vitro $(28,29)$. Finally, in vivo, estrone does not affect the disappearance of thyroxine from the plasma of rats or rabbits $(30,31)$.

Thus, it is possible that the slowing of thyroxine turnover induced by estrogens during the present studies may have resulted either from a direct effect of these hormones on the cellular degradation of thyroxine or from an effect on cellular oxidative metabolism reflected secondarily in delayed thyroxine turnover. However, there is no substantial evidence to suggest that this was the case. On the other hand, there is considerable evidence to indicate that the slowing of thyroxine turnover herein produced resulted from an increase in the binding activity of TBG. In vitro, the static dis- tribution of thyroxine between cellular and extracellular binding proteins is conditioned by their relative abundance and binding avidity $(5,6$, 32). An increase in the binding activity of proteins in the suspending medium favors retention of thyroxine in the extracellular phase. If, as seems likely, similar relationships pertain in vivo, then increases in TBG should decrease the proportion of peripheral hormone within cellular confines. Since the degradation of thyroxine is an intracellular event, this should, in turn, diminish the fractional rate of turnover of hormone within the thyroxine space as a whole $(12,33)$.

In the present experiments, studies in Patient 6 illustrate the rapidity with which slowing of thyroxine turnover may follow the exhibition of diethylstilbestrol. This rapid change might suggest a direct cellular effect of the estrogen were it not that circulating TBG increased with equal rapidity. In Patient 9, retarded turnover of thyroxine and augmentation of TBG persisted after cessation of estrogenic therapy. Although withdrawal vaginal bleeding had occurred in this interval, it remains possible that diminishing but physiologically significant stores of estrogen persisted during that time.

Additional evidence that estrogenic effects on the fractional turnover of thyroxine result from altered hormonal binding has recently been obtained in two patients whose sera demonstrated spontaneous abnormalities in the thyroxine-binding capacity of TBG. The first patient, recently reported by Beierwaltes and Robbins (34), displayed an apparently idiopathic increase in TBG, associated with abnormalities in the turnover of thyroxine remarkably similar to those induced by estrogens in the present studies. The plasma of the second patient was virtually devoid of TBG. Administration of estrogen induced edema and gynecomastia, but the binding capacity of TBG was not increased and the kinetics of thyroxine metabolism were unaltered (14).

From the foregoing observations in isolated cellular systems and in patients, it would appear that the effects of estrogenic hormones on the kinetics of thyroxine metabolism are indeed the result of concomitantly induced changes in the binding activity of TBG. Rate limitations imposed by TBG on the removal of thyroxine from its peripheral distribution compartment might be exerted 
through effects on either the excretory or the degradative disposal of hormone, or both. Since urinary losses of intact thyroxine contribute but very slightly to the total disposal of the hormone $(35,36)$, decreased urinary excretion of iodine could not have accounted for the slowing of fractional turnover rates induced by estrogens. In contrast, fecal excretion of iodinated organic compounds contributes significantly to total hormone turnover $(7,37)$. Accordingly, estimates of the fraction of hormone removed from the thyroxine space by fecal excretion before and during estrogenic therapy were made in seven patients. Variable, seemingly random alterations in calculated values for the fractional removal of hormone by the fecal route $\left(F_{\max }\right)$ occurred. Such variations may have been attributable to inaccuracies in the estimation of $F_{\max }$. Nevertheless, fractional fecal excretion of thyroxine appeared to decrease during estrogenic therapy in five out of seven patients. For the group as a whole, however, changes in $F_{\max }$ were not statistically significant. Values for the rate of fecal clearance of hormone, calculated as the product of the hormonal clearance rate and the fecal fraction, were decreased in six of seven patients, and for the group as a whole the decrease was significant at the 5 per cent level. Nonexcretory, presumably degradative clearances, calculated as the difference between total and fecal clearance rates were diminished during estrogenic therapy in all patients. For the group as a whole, this change was highly significant $(p<0.01)$. It would thus appear that both the degradative metabolism and the fecal excretion of thyroxine are limited by the association between thyroxine and TBG. This conclusion is consonant with the observations of Rasmussen (38) and of Myant (39), which indicate that the fecal or biliary elimination of thyroxine is increased when hormonal binding sites in the plasma are more nearly saturated than normal.

The present studies can be divided into three periods: 1) a control period in which PBI and TBG were constant ; 2) a period of two to four weeks beginning shortly after the administration of estrogen, in which PBI and TBG were rising ;4

\footnotetext{
4 In an earlier study from this laboratory (13), a consistent increase in PBI was not found during estrogenic therapy in patients with treated myxedema. However, the present studies should afford a more reliable index
}

and 3) a period in which PBI and TBG, though increased, were again constant, despite continued administration of estrogen. In patients with treated myxedema, hormonal supplies were constant throughout the period of observation. Constancy of PBI's during the control period would indicate that influx and removal of hormone were equal. Since this was also true during the final period, hormonal disposal must then have returned to control levels. This was confirmed, within the limits of experimental error, by kinetic studies with labeled thyroxine. These further indicated that the quantity of hormone removed by both fecal and degradative routes had returned to normal by that time.

The second period may be considered a phase during which the peripheral metabolism of hormone was re-adjusting to the effects of estrogenic therapy. During this time, hormonal removal must have declined below control values, since both the concentration and total content of hormone within the thyroxine space were increasing. Presumably, this reflected a sparing of hormone by both fecal and degradative mechanisms. If so, then the quantity of hormone available to intracellular degradative sites must have declined below control values. The magnitude of this tissue deficit of hormone at any moment in time cannot be assessed. However, for the entire period of approximately one month's duration, a mean positive balance of $193 \mu \mathrm{g}$ of hormonal iodine per patient was obtained. If fractional removal of hormone declined abruptly after initiation of estrogenic therapy while the increase in PBI occurred more slowly, then the daily deficit of hormone within the tissues would have been relatively large during early portions of the period and would have become progressively smaller as reequilibration was approached. If, however, fractional turnover of hormone declined slowly and PBI increased pari passu, then there would have

of estrogenic effects in that a larger number of patients was studied and PBI's were determined more frequently. In addition, it can be demonstrated mathematically that when hormonal supplies are constant and fractional turnover of hormone declines, the magnitude of the resulting increase in PBI is proportional to the control PBI value (40). Accordingly, patients in the present study were maintained on somewhat larger doses of thyroid hormone in order to insure the establishment of control PBI's well within the normal range. 
occurred only a slight daily deficit in hormonal delivery of relatively uniform magnitude throughout the period. Since TBG increased progressively throughout this phase, the latter possibility seems the more likely.

While, in patients with treated myxedema, the postulated sequence of events is relatively simple, in patients with functioning thyroid glands it is potentially more complex. Here, it might be anticipated that the reduction in hormonal flux to the tissues would result in enhanced secretion of thyrotropin, since hypophyseal homeostatic mechanisms seem directed toward maintaining constant supplies of thyroid hormone to peripheral tissues (41). Consequent stimulation of the synthesis and release of thyroid hormone would serve to diminish the deficit in peripheral hormonal supplies and to hasten return to a steady state. However, it is questionable whether such an increase in thyroidal function actually occurs. Diethylstilbestrol has been found to increase the rate of release of thyroidal $\mathrm{I}^{131}$ of euthyroid patients undergoing hypophyseal suppression by triiodothyronine (42). On the other hand, evidence of hypophyseal activation has not been obtained, since repeated efforts to demonstrate an increase in the thyroidal uptake of iodine during therapy with diethylstilbestrol have failed $(18,43)$. It may be that the deficit in peripheral hormonal supplies induced by the administration of estrogens is never sufficiently great to activate secretion of TSH. Alternatively, previous studies may have been performed during the final phase of the response to estrogens, when a new steady state had been achieved.

Findings in patients with thyrotoxicosis were of interest in several respects. Previously reported abnormalities in the kinetics of thyroxine metabolism were confirmed. Thus, three of four patients displayed accelerated fractional rates of thyroxine turnover both prior to treatment $(7$, $37,44)$ and following restoration of a eumetabolic state by propylthiouracil (45). During administration of diethylstilbestrol, increased binding activity of TBG occurred in all patients. Concomitantly, fractional rates of turnover became at least as slow as those found subsequently during antithyroid therapy. In Patients 14 and 15, the remaining findings were similar to those seen in eumetabolic subjects, in that PBI's increased, hor- monal clearance rates declined, daily hormonal disposal remained essentially unaltered, and metabolic status was unchanged.

In Patients 12 and 13, strikingly different findings obtained. Here, despite marked decreases in hormonal clearance rates, PBI's failed to increase. This could have occurred only if the flux of hormone from the thyroid gland to the periphery had declined during administration of estrogen. From the data of other workers (46), it would appear that estrogens may slow the rate of release of glandular iodine in some patients with thyrotoxicosis. Because of the decreased hormonal clearance rates and the unchanged PBI's, daily hormonal disposal in these patients decreased to values approaching those found during antithyroid therapy. At the same time, there occurred a marked amelioration of the signs and symptoms of thyrotoxicosis and reduction in basal metabolic rate. This favorable response was reminiscent of the occasional amelioration of thyrotoxicosis by estrogens reported by earlier workers (47). From the present data, it is evident that the symptomatic remission of thyrotoxicity, which estrogens may occasionally induce, results from thyroidal and peripheral effects reflected in decreased hormonal disposal. rather than from direct anti-oxidative effects within the tissues. However, those factors which account for the variability in the thyroidal response to estrogens, as seen in this and earlier studies, remain an intriguing enigma.

\section{SLMMARY}

The effects of diethylstilbestrol and of estradiol benzoate upon the kinetics of thyroxine metabolism have been assessed in patients with intact thyroidal function, treated myxedema, or Graves' disease.

In all subjects, estrogen induced an increase in the binding avidity of the thyroxine-binding globulin (TBG), which was accompanied by marked retardation of the fractional rate of peripheral turnover of $\mathrm{I}^{131}$-labeled thyroxine. In eumetabolic subjects, concentration of protein-bound iodine (PBI) increased sufficiently to restore the daily disposal of hormonal iodine to normal values.

Two of four thyrotoxic patients failed to demonstrate expected increases in the concentration of PBI, and exhibited amelioration of symptoms and of hypermetabolism during administration of es- 
trogen. During this period, daily hormonal disposal rates approached values found subsequently during restoration of eumetabolism by propylthiouracil.

These observations are consistent with the hypothesis that thyroxine-binding by TBG exerts a rate-limiting effect upon the peripheral metabolism of this hormone.

\section{APPENDIX}

In the foregoing manuscript, the following terms have been employed. These were described in detail in an earlier communication (7).

TDS, thyroxine distribution space; the virtual volume of body fluids through which exchangeable thyroxine would be distributed were it present throughout at the same concentration at which it exists in the plasma.

PBI, concentration of hormonal iodine in the plasma, and, by definition, the geometrical mean concentration of hormonal iodine in the TDS; assumed to represent solely iodine in thyroxine.

ETT, extrathyroidal thyroxine; the total quantity of thyroxine within the TDS, in terms of its content of iodine.

$\mathrm{k}$, Fractional rate of turnover of thyroxine; the proportion of ETT removed from the TDS per unit time.

$\mathrm{T}_{\frac{1}{1}}$, thyroxine half-time; the time required for half of the ETT to be removed from the TDS.

$\mathrm{C}$, thyroxine clearance rate; the volume of plasma which contains an amount of thyroxine equal to that removed from the TDS per unit time. Defined as "volume turnover, V" in an earlier communication (7).

$\mathrm{D}$, hormonal disposal rate; the quantity of hormone removed from the TDS per unit time, in terms of its content of iodine.

$F_{\max }$, the proportion of $\mathrm{D}$ accounted for by fecal excretion of hormone; fecal clearance, the volume of plasma which contains a quantity of hormone equal to that lost in the feces per unit time; degradative clearance, the volume of plasma which contains a quantity of hormone equal to that removed by nonexcretory pathways per unit time; fecal excretion, the quantity of hormone excreted in the feces per unit time; degradative rate, the quantity of hormone removed by nonexcretory pathways per unit time.

$\mathrm{ETT}=\mathrm{PBI} \times \mathrm{TDS} . \quad \mathrm{C}=\mathrm{TDS} \times \mathrm{k} . \quad \mathrm{D}=\mathrm{C} \times \mathrm{PBI}$ $=\mathrm{ETT} \times \mathrm{k} . \quad \mathrm{T}_{\frac{1}{2}}=0.693 / \mathrm{k} . \quad$ Fecal clearance $=\mathrm{C} \times \mathrm{F}_{\max .}$ Degradative clearance $=\mathrm{C}-$ fecal clearance. Fecal excretion $=$ fecal clearance $\times \mathrm{PBI}=\mathrm{D} \times \mathrm{F}_{\max }$. Degradative rate $=$ degradative clearance $\times \mathrm{PBI}=\mathrm{D}-$ fecal excretion.

\section{REFERENCES}

1. Gordon, A. H., Gross, J., O'Connor, D., and PittRivers, R. Nature of the circulating thyroid hormone-plasma protein complex. Nature (Lond.) 1952, 169, 19.
2. Larson, F., Deiss, W. P., and Albright, E. C. Localization of protein-bound radioactive iodine by filter paper electrophoresis. Science 1952, 115, 626.

3. Robbins, J., and Rall, J. E. The interaction of thyroid hormones and protein in biological fluids. Recent Progr. Hormone Res. 1957, 13, 161.

4. Ingbar, S. H. Pre-albumin: A thyroxine-binding protein of human plasma. Endocrinology 1958, 63, 256.

5. Crispell, K. R., and Coleman, J. A study of the relative binding capacity of plasma proteins, intact human red cells, and human red cell stroma for radioactive I-131 labeled L-thyroxine. J. clin. Invest. 1956, 35, 475.

6. Freinkel, N., Ingbar, S. H., and Dowling, J. T. The influence of extracellular thyroxine-binding protein upon the accumulation of thyroxine by tissue slices. J. clin. Invest. 1957, 36, 25.

7. Ingbar, S. H., and Freinkel, N. Simultaneous estimation of rates of thyroxine degradation and thyroid hormone synthesis. J. clin. Invest. 1955, 34, 808.

8. Volwiler, W., Goldsworthy, P. D., MacMartin, M. P., Wood, P. A., Mackay, I. A., and Fremont-Smith, $\mathrm{K}$. Biosynthetic determination with radioactive sulfur of turn-over rates of various plasma proteins in normal and cirrhotic man. J. clin. Invest. 1955, 34, 1126.

9. Robbins, J., Rall, J. E., and Petermann, M. L. Thyroxine-binding by serum and urine proteins in nephrosis. Qualitative aspects. J. clin. Invest. 1957, 36, 1333.

10. Federman, D. D., Robbins, J., and Rall, J. E. Effects of methyl testosterone on thyroid function, thyroxine metabolism, and thyroxine-binding protein. J. clin. Invest. 1958, 37, 1024.

11. Richards, J. B., Dowling, J. T., and Ingbar, S. H. Alterations in the plasma transport of thyroxine in sick patients and their relation to the abnormality in Graves' disease (abstract). J. clin. Invest. 1959, 38, 1035.

12. Ingbar, S. H., and Freinkel, N. The thyroid hormone in Hormones in the Blood, H. N. Antoniades, Ed. Boston, Little, Brown \& Co. In press.

13. Dowling, J. T., Freinkel, N., and Ingbar, S. H. Effect of diethylstilbestrol on the binding of thyroxine in serum. J. clin. Endocr. 1956, 16, 1491.

14. Ingbar, S. H. Unpublished observations.

15. Dowling, J. T., Freinkel, N., and Ingbar, S. H. Thyroxine-binding by sera of pregnant women, newborn infants, and women with spontaneous abortion. J. clin. Invest. 1956, 35, 1263.

16. Robbins, J., and Nelson, J. H. Thyroxine-binding by serum protein in pregnancy and in the newborn. J. clin. Invest. 1958, 37, 153.

17. Snedecor, G. W. Statistical Methods Applied to Experiments in Agriculture and Biology, 4th ed. Ames, Iowa, The Iowa State College Press, 1946. 
18. Engstrom, W. W., and Markardt, B. Influence of estrogen on thyroid function. J. clin. Endocr. 1954, 14, 215.

19. Engbring, N. H., and Engstrom, W. W. Effects of estrogen and testosterone on circulating thyroid hormone. J. clin. Endocr. 1959, 19, 783.

20. Gordan, G. S., and Elliott, H. W. The action of diethylstilbestrol and some steroids on the respiration of rat brain homogenates. Endocrinology 1947, 41, 517 .

21. Guidry, M. A., Segaloff, A., and Altschul, A. M. The effect of a-estradiol, some of its esters and estrone on the respiration of tissue homogenates. Endocrinology 1952, 50, 29.

22. Wade, R., and Jones, H. W., Jr. Effect of progesterone on oxidative phosphorylation. J. biol. Chem. 1956, 220, 553.

23. Bodansky, M., and Duff, V. B. The influence of pregnancy on resistance to thyroxine, with data on the creatine content of the maternal and fetal myocardium. Endocrinology 1936, 20, 537.

24. Danforth, D. N., Greene, R. R., and Ivy, A. C. The effect of female sex hormones upon the oxygen consumption rate of normal rats, and upon the tolerance to desiccated thyroid. Fndocrinology 1937, 21, 361.

25. Sherwood, T. C. The relation of estrogenic substances to thyroid function and respiratory metabolism. Amer. J. Physiol. 1938, 124, 114.

26. Doisy, R. J., and Lardy, H. A. Effect of certain steroids on metabolic rate of hyperthyroid rats. Amer. J. Physiol. 1957, 190, 142.

27. Sherwood, T. C. The effect of stilbestrol on the basal metabolism of experimental hyperthyroid rats. Endocrinology 1940, 26, 693.

28. Cruchaud, S., Vannotti, A., Mahaim, C., and Deckelmann, J. The in-vitro effect of methylthiouracil and oestradiol monophosphate on the conversion of thyroxine to triiodothyronine by kidney slices. Lancet 1955, 2, 906.

29. Yamazaki, E., and Slingerland, D. W. The in vitro metabolism of thyroxine, triiodothyronine and their acetic and propionic acid analogues. Endocrinology 1959, 64, 126.

30. Feldman, J. D. Effect of estrogen on the peripheral utilization of thyroid hormones. Amer. J. Physiol. 1957, 188, 30.

31. Beckers, C., Lulling, J., and de Visscher, M. Influence de la folliculine sur le métabolisme de la radiothyroxine. Acta endocr. (Kbh.) 1959, 30, 242.

32. Hamolsky, M. W., Stein, M., and Freedberg, A. S. The thyroid hormone-plasma protein complex in man. II. A new in vitro method for study of "uptake" of labelled hormonal components by human erythrocytes. J. clin. Endocr. 1957, 17, 33.

33. Ingbar, S. H., and Freinkel, N. Regulation of the peripheral metabolism of the thyroid hormones. Recent Progr. Hormone Res. In press.

34. Beierwaltes, W. H., and Robbins, J. Familial increase in the thyroxine-binding sites in serum alpha globulin. J. clin. Invest. 1959, 38, 1683.

35. Myant, N. B., and Pochin, E. E. The metabolism of radiothyroxine in man. Clin. Sci. 1950, 9, 421.

36. Rall, J. E. Iodine compounds in the blood and urine of man. J. clin. Endocr. 1950, 10, 996.

37. Berson, S. A., and Yalow, R. S. Quantitative aspects of iodine metabolism. The exchangeable organic iodine pool, and the rates of thyroidal secretion, peripheral degradation and fecal excretion of endogenously synthesized organically bound iodine. J. clin. Invest. 1954, 33, 1533.

38. Rasmussen, H. Thyroxine metabolism in the nephrotic syndrome. J. clin. Invest. 1956, 35, 792.

39. Myant, N. B. Relation between the biliary clearance rate of thyroxine and the binding of thyroxine by the serum proteins. J. Physiol. (Lond.) 1957, 135, 426.

40. Ingbar, S. H., and Freinkel, N. ACTH, cortisone and the metabolism of iodine. Metabolism 1956, 5 , 652.

41. Ingbar, S. H. Implications of thyroxine turnover in man in Progress in Clinical Endocrinology, E. B. Astwood, Ed. New York, Grune \& Stratton, Inc. In press.

42. Dowling, J. T., Ingbar, S. H., and Freinkel, N. The role of thyroxine-binding interactions in the thyroidal release of hormone. Clin. Res. 1958, 6, 24.

43. Dowling, J. T., Ingbar, S. H., and Freinkel, N Failure of diethylstilbestrol to affect thyroidal accumulation and renal clearance of $\mathrm{I}^{131}$. J. clin. Endocr. 1959, 19, 1245.

44. Sterling, K., and Chodos, R. B. Radiothyroxine turnover studies in myxedema, thyrotoxicosis, and hypermetabolism without endocrine disease. J. clin. Invest. 1956, 35, 806.

45. Ingbar, S. H., and Freinkel, N. Studies of thyroid function and the peripheral metabolism of $\mathrm{I}^{131}$ labeled thyroxine in patients with treated Graves' disease. J. clin. Invest. 1958, 37, 1603.

46. Solomon, D. H. Factors affecting the fractional rate of release of radioiodine from the thyroid gland in man. Metabolism 1956, 5, 667.

47. Starr, P., and Patton, H. Observations of remissions in hyperthyroidism induced by pregnancy urine extract. Ann. intern. Med. 1936, 8, 825. 